\title{
An Accurate and Reproducible Absorptiometric Technique for Determining Bone Mineral Content in Newborn Infants
}

\author{
FRANK R. GREER, (18) JOY LANE, SCOTT WEINER, AND RICHARD B. MAZESS \\ Departments of Pediatrics and Medical Physics, University of Wisconsin Center for Health Sciences, \\ Madison, Wisconsin, USA
}

\begin{abstract}
Summary
At the Bone Mineral Laboratory of the University of Wisconsin a microcomputer-based digital read-out system was designed specifically for determining bone mineral content (BMC) and bone width (BW) in newborn infants with the following features: (1) high accuracy and precision; (2) high reproducibility in vivo; (3) direct read-out of $\mathrm{BMC}$ and $\mathrm{BW}$; (4) automatic data calibration; and (5) use of a low activity $\left.I^{125} \mathrm{I}\right]$ source $(<50 \mathrm{mCi})$. BMC and $B W$ were determined on the left radius on a series of 114 newborn infants of all gestational ages and a curve for intrauterine bone mineral content extrapolated from the data. Accuracy of the photon absorptiometric system was assessed by measuring BMC on a series of nine small bone sections $(29-212 \mathrm{mg} / \mathrm{cm})$ and confirmed by subsequent ashing of these bone sections $(r=0.99)$. Short-term precision (weekly, coefficient of variation $1.7 \%$ ) and long-term precision (monthly, coefficient of variation $2.1 \%$ ) for measuring BMC were determined by multiple determinations on a four-chambered bone phantom calibrated with the bone sections. Immediate reproducibility (without repositioning the arm) for the 4-6 scans performed for each determination of $\mathrm{BMC}$ and $\mathrm{BW}$ was good with a mean coefficient of variation of $3.9 \%$ for BMC and $3.6 \%$ for $\mathrm{BW}$. In 84 infants, repositioning error was determined by repeating the measurement of $\mathrm{BMC}$ and $\mathrm{BW}$ after repositioning the arm. The correlation coefficients between measurements before and after repositioning the arm were 0.97 for $\mathrm{BMC}$ and 0.95 for BW. BMC correlated well with gestational age $(r=0.92)$, birth weight $(r=0.89)$ and bone width $(r=0.92)$. BW also correlated with gestational age $(r=0.84)$ and birth weight $(r=$ 0.85 ). A multiple linear regression analysis of BMC versus $B W$, gestational age, and birth weight was done. The correlation coefficient between the predicted BMC from these variables and measured BMC was 0.95 . Photon absorptiometry can be used with high accuracy, precision, and reproducibility in vivo in newborn infants. BMC correlates with gestational age, birth weight, and bone width.
\end{abstract}

\section{Abbreviations}

BMC, bone mineral content

BW, bone width

IUBMC, intrauterine bone mineral content

Since the report by Minton et al. (9), the technique of photon absorptiometry has held promise for determining changes in bone mineral content (BMC) in the newborn, particularly in the verylow-birth-weight infant where disorders of bone mineralization are common. This previous work has not been verified nor has the accuracy or reproducibility in vivo of the technique been established for the small bones of the newborn infant. At the Bone Mineral Laboratory of the University of Wisconsin a microcomputer-based digital read-out system was designed specifically for determining BMC and bone width (BW) in newborn infants with the following features: (1) high accuracy and precision; (2) high reproducibility in vivo; (3) direct read-out of BMC and BW; (4) automatic data calibration; and (5) use of a low activity $\left.{ }^{[25} \mathrm{I}\right]$ source $(<50 \mathrm{mCi})$. Subsequently, BMC and BW were determined on a series of 114 newborn infants of all gestational ages and a curve for intrauterine bone mineral content (IUBMC) extrapolated from the data (14).

\section{MATERIALS AND METHODS}

Photon absorptiometry. BMC and BW were measured by a photon absorptiometric system in which a collimated, 2-mm diameter photon beam from a low activity, $\left.{ }^{125} \mathrm{I}\right]$ "spent" source $(20$ $50 \mathrm{mCi}$ ) passes beneath the arm (bone) to be scanned (12). A collimated scintillation detector placed over the arm was equipped with a mechanism to allow for simultaneous movement of the collimated detector and $\left[{ }^{125} \mathrm{I}\right]$ source, with a scan speed of $0.4 \mathrm{~mm} /$ sec. Changes in beam intensity are due to the attenuation by bone mineral, and the integrated attenuation is proportional to the mass $(\mathrm{mg}$ per $\mathrm{cm}$ ) of mineral in the scan path. The length of the scan path is proportional to the width of the bone, the bone edge being detected by a $10 \%$ decrease from the baseline count in tissue adjacent to the bone. The system includes a nuclear counting device (Baird-Atomic Model 530) and a microcomputer (Radio Shack TRS-80) with a specially designed interface for counting pulses and controlling the motor of the scanner.

All measurements of BMC and BW were made at a site on the distal left radius located by external measurement at a position $1 / 3$ of the distance from the distal end. The infant's forearm was placed in a lucite holding device, surrounded with a segment of water-filled dialysis tubing, and compressed with a lucite plate, thereby assuring a constant soft tissue equivalent material around the bone (1). A series of four to six determinations of BMC and $\mathrm{BW}$ were done at each site and the average value used. The radiation dose from a series of four scans did not exceed $13 \mathrm{mrad}$ as measured by thermoluminescent dosimetry with lithium fluoride chips. This is comparable to the radiation dose from a pediatric chest $\mathrm{x}$-ray, though the path of the scan is only $0.3 \mathrm{~mm}$ wide.

To determine the accuracy of the absorptiometric system, BMC was measured on a series of nine small bone sections and confirmed by subsequent ashing of these bone sections (10) (Fig. 1). Three of the bones were from premature infants, the remaining six were of avian origin. The mineral content of the bone sections ranged from $29-212 \mathrm{mg} / \mathrm{cm}$ compared to an adult range of 600 $1500 \mathrm{mg} / \mathrm{cm}$ at the $1 / 3$ distal radius (7). The BMC of a normal fullterm infant is about $90 \mathrm{mg} / \mathrm{cm}$ (9). There was a high correlation coefficient for the linear regression of ashed weight versus measured BMC, $r=0.99$ with a standard error of estimate (S.E.E.) of $2.1 \mathrm{mg} / \mathrm{cm}$. Subsequently, this regression line was used to calibrate a four-chambered bone phantom (precision bored plastic chambers filled with a solution of potassium phosphate) used in daily 
calibration of the scanner (15). Precision of the system was determined by making multiple measurements of the bone phantom. Short-term precision of the phantom was excellent as shown by coefficients of variation of $1.7 \%$ and $0.7 \%$ for weekly determined means of BMC and BW respectively. Long-term precision (monthly determined means) was $2.1 \%$ for BMC and $0.8 \%$ for BW.

Population. Measurements of $\mathrm{BMC}$ and $\mathrm{BW}$ were made during the first week of life at a mean age of 3.0 days, in 114 Caucasian, appropriate for gestational age infants from $22-42 \mathrm{wk}$ gestation. Gestational age was determined from the history of the last menstrual period and corroborated by physical examination for those infants greater than $27 \mathrm{wk}$ gestational age. For those infants less than or equal to $27 \mathrm{wk}$, ultrasound (biparietal diameter) was

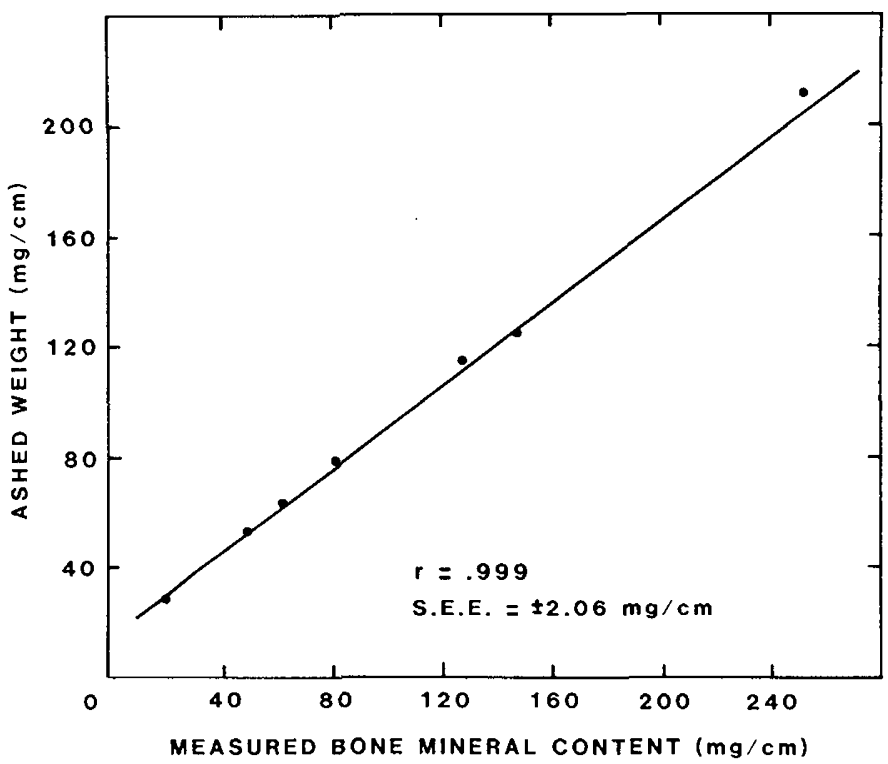

Fig. 1. Weight of nine $1-\mathrm{cm}$ small bone sections (three from premature infants, six of avian origin) after ashing $v s$ bone mineral content as measured by photon absorptiometry. used as the second corroborator of gestational age. If there was more than a 2-wk discrepancy between the two determinations of gestational age, the infant was excluded from the study. All infants were admitted to the nurseries of Madison General Hospital. All were free from congenital malformations and persistent metabolic acidosis $(>8 \mathrm{~h})$. Sixty-seven of the infants were less than $38 \mathrm{wk}$ gestational age and 30 infants were 32 wk gestational age or less. Seven of the most premature infants died within a few hours of birth and were measured within $12 \mathrm{~h}$ after death. A series of 4-6 scans were done on each infant and the average value used. Interassay reproducibility in vivo was tested in 84 infants by repositioning and remeasuring the arm, and repeating the scan on the same day. Informed consent was obtained from all parents.

\section{RESULTS}

Results for BMC and BW are shown in Table 1. Males as a group had a higher BMC than females at each gestational age, though the differences were not significant.

Immediate reproducibility (without repositioning of the arm) for the 4-6 scans performed for each determination of BMC and

Table 1. Results of radial bone mineral content $(B M C)$ and bone width in 114 appropriate for gestational age infants from 22-42 wk gestational age

\begin{tabular}{crcrcc}
\hline $\begin{array}{c}\text { Gestational age } \\
(\text { wk })\end{array}$ & $n$ & $\begin{array}{c}\text { BMC } \\
(\mathrm{mg} / \mathrm{cm})\end{array}$ & S.D. & $\begin{array}{c}\text { Bone } \\
\text { width } \\
(\mathrm{mm})\end{array}$ & S.D. \\
\hline 22 & 1 & 20.1 & & 2.5 & \\
$24-25$ & 3 & 26.3 & 7.7 & 2.9 & 0.5 \\
$26-27$ & 3 & 32.5 & 11.9 & 3.0 & 0.5 \\
$28-29$ & 6 & 38.6 & 7.9 & 3.5 & 0.5 \\
$30-31$ & 11 & 43.0 & 7.5 & 3.4 & 0.3 \\
$32-33$ & 14 & 46.9 & 8.0 & 3.7 & 0.5 \\
$34-35$ & 13 & 54.9 & 11.0 & 4.0 & 0.5 \\
$36-37$ & 16 & 71.4 & 12.1 & 4.5 & 0.4 \\
$38-39$ & 24 & 92.6 & 14.0 & 5.1 & 0.5 \\
$40-41$ & 19 & 94.1 & 9.6 & 5.3 & 0.6 \\
42 & 4 & 100.1 & 23.9 & 5.2 & 0.9
\end{tabular}

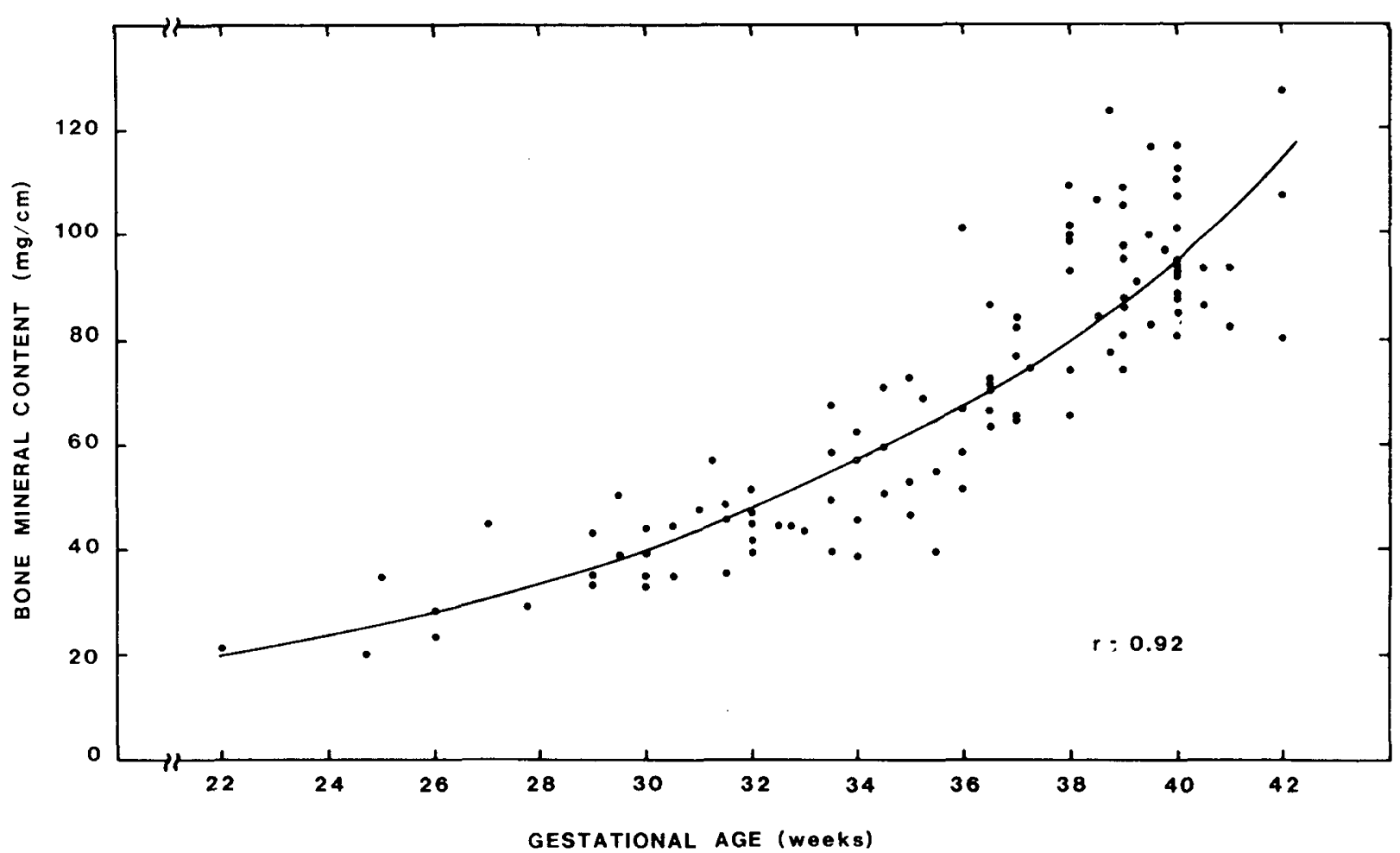

Fig. 2. Bone mineral content as measured by photon absorptiometry in the left radius of 114 newborn infants vs gestational age. 


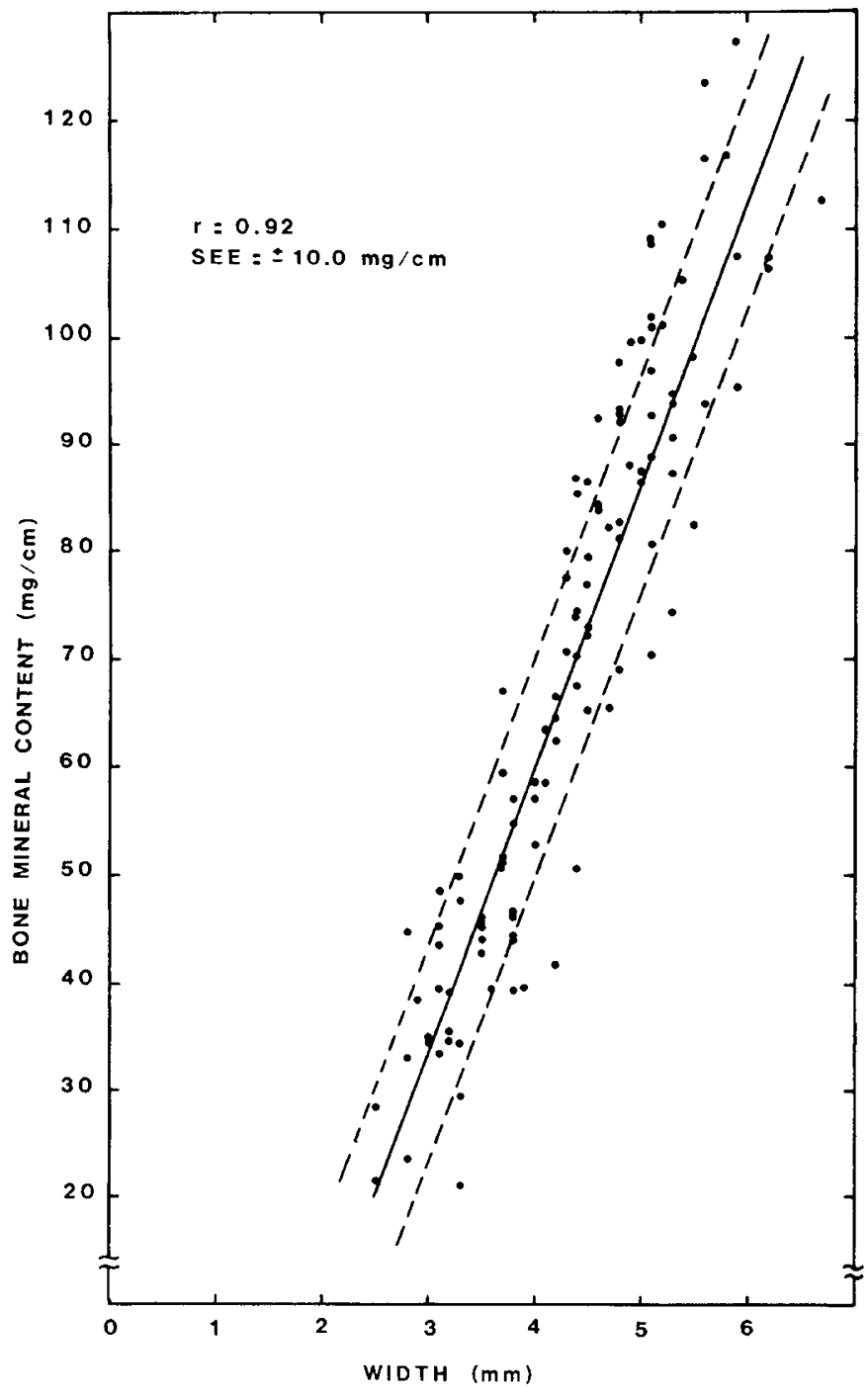

Fig. 3. Bone mineral content vs bone width as measured by photon absorptiometry in the left radius of 114 newborn infants of all gestational ages. Dotted lines represent \pm 1 S.E.E.

BW was good with a mean coefficient of variation of $3.9 \%$ for $\mathrm{BMC}$ and $3.6 \%$ for $\mathrm{BW}$ in the 114 infants. The repositioning error was small in 84 infants who were remeasured; the correlation coefficient between measurements before and after repositioning the arm was 0.97 (S.E.E. $=6.0 \mathrm{mg} / \mathrm{cm}$ ) for $\mathrm{BMC}$ and 0.95 (S.E.E. $=0.4 \mathrm{~mm}$ ) for BW. Reproducibility was not affected by gestational age or birth weight.

The relationship of BMC to gestational age (GA) was examined using both linear and curvilinear regression analysis. An exponential curve $\left(B M C=3.47 \mathrm{e}^{0.082 \mathrm{GA}}\right)$ fit the data more closely $(r=0.92$ versus $r=0.88)$ than did the linear regression $(\mathrm{BMC}=5.06 \mathrm{GA}$ 111). The curvilinear regression was used to define a curve that could be extrapolated to the intrauterine period (Fig. 2); however, the linear relationship was adequate over the period from $28-42$ wk as has been previously reported (14). There was a linear relationship of BMC with birth weight $(r=0.89$, S.E.E. $=12.1$ $\mathrm{mg} / \mathrm{cm}$ ). Likewise, BW correlated with gestational age and birth weight, the correlation coefficients being 0.84 and 0.85 , respectively. A high correlation (linear) was found between BMC and BW (Fig. 3). This correlation coefficient was 0.92 with an S.E.E. of $10.0 \mathrm{mg} / \mathrm{cm}$.

Finally, multiple linear regression analysis of $\mathrm{BMC}$ versus $\mathrm{BW}$, gestational age, and birth weight was done. The correlation coefficient between the predicted BMC from these variables and measured BMC was $r=0.95$.

\section{DISCUSSION}

Photon absorptiometry has been shown to be a reliable, noninvasive method for determining bone mineral content. The accuracy and precision of photon absorptiometry have been demonstrated in adults (1). Conventional radiologic methods do not detect decreases in bone mineral of less than $30-40 \%(4,6)$, and quantitative morphometric and photondensitometric methods can determine bone loss within only broad limits (10-20\% error) (8). There is limited experience using computed tomography to measure bone mineral (2). Bone biopsy, tetracycline labeling, technetium scan or total skeletal biochemical analysis are not practical for serial determinations of bone mineral in neonates.

The results of photon absorptiometry in newborn infants of gestational ages from 28-42 wk including an intrauterine bone mineral curve have been reported $(9,14)$. But the accuracy of the system for measuring small bones has not been previously reported nor have the results for reproducibility in vivo. A criticism of the photon absorptiometric technique in infants has been its reproducibility, because the point of measurement on the radius is located by external measurement and the subject must not move the arm during the measurement. For isolated bone sections, it has been shown that the BMC is not affected significantly by the amount of soft tissue around the bone nor by the orientation of the bone within the soft tissue (12). For bones in vivo, it has been reported that rotation of the forearm affects the measurement of BMC; orientation of the upper arm does not affect measurements at the distal site (11). In this study, we have clearly demonstrated that the system is accurate for newborn infants and that measurements can be reproduced despite the inherent problems with repositioning and arm orientation.

Our results for BMC (Table 1, Fig. 2) are similar to those previously reported, despite the use of a lower activity, "spent" source $(20-50 \mathrm{mCi}$ versus $50-200 \mathrm{mCi})(9)$. BMC for infants $37-41$ wk gestational age was previously reported to be $90 \pm 9 \mathrm{mg} / \mathrm{cm}$ ( \pm S.E.) (9), whereas the BMC for the same gestational age range in our study is $91 \pm 2 \mathrm{mg} / \mathrm{cm}$. The linear correlation coefficient for BMC versus gestational age was 0.83 in the previous study (9) and 0.88 in the present, whereas the correlation coefficients for $\mathrm{BMC}$ versus birth weight were 0.82 and 0.89 , respectively.

In the present study (Fig. 2), we have used a curvilinear regression to describe the relationship between BMC and gestational age and extrapolated the data to a curve of intrauterine bone mineral content. This is logical as the relationships between fetal calcium accretion and gestational age and fetal skeletal weight and gestational age are curvilinear $(3,5,13)$.

The results for BW, as measured by photon absorptiometry, have not been previously reported in infants. The relationship between BMC and BW (Fig. 3) may be useful in identifying disorders of bone mineral metabolism in low birth weight infants. In such rapidly growing infants, we speculate that the bone width continues to increase due to increased matrix formation, whereas $\mathrm{BMC}$ may decrease or remain unchanged due to a relative decrease in deposition of bone mineral secondary to insufficient mineral intake. The technique of photon absorptiometry may thus be useful in identifying and treating infants with such nutritional problems.

In conclusion, photon absorptiometry can be used with high accuracy, precision, and reproducibility in vivo in newborn infants. BMC shows a high correlation with gestational age, birth weight and bone width.

\section{REFERENCES AND NOTES}

1. Cameron, J. R., Mazess R. B., and Sorenson, J. A.: Precision and accuracy of bone mineral determination by direct photon absorptiometry. Investigative Radiology, 3: 141 (1968).

2. Exner, G. U. and Prader, A.: Bone densitometry using computed tomography. Part I: Selective determination of trabecular bone density and other bone mineral parameters. Normal values in children and adults. Brit. J. Radiol. 52: i4 (1979).

3. Givens, M. H. and Macy, I. G.: The chemical composition of the human fetus. J. Biol. Chem., 102: 7 (1933). 
4. Griffiths, H. J., Zimmerman, R. E., Barty, A., and Snider, R.: The use of photon absorptiometry in the diagnosis of renal osteodystrophy. Radiology, 109: 277 (1973).

5. Iob, V. I. and Swanson, W. W.: Mineral growth of the human fetus. Am. J. Dis. Child., 47: 302 (1934)

6. Lachman, E.: Osteoporosis: the potentialities and limitations of its roentgenologic diagnosis. Am. J. Roentgenol., 74: 712 (1955).

7. Mazess, R. B. and Cameron, J. R.: Bone mineral content in normal U.S. whites in Mazess, R. B. (Ed.): International Conference on Bone Mineral Measurement, publication 74-683, U.S. Dept. of Health, Education and Welfare, 1974 pp. 228-238.

8. Mazess, R. B., Cameron, J. R., and Sorenson, J. A.: A comparison of radiological methods for determining bone mineral content, in Whedon, G. D., Cameron, J. R. (Eds.): Progress in Methods of Bone Mineral Measurement. U.S. Dept. of Health, Education and Welfare, 1970, pp. 455-479.

9. Minton, S. D., Steichen, J. J., and Tsang, R. C.: Bone mineral content in term and preterm appropriate-for-gestational-age infants. J. Pediatr., 95: 1037 (1979).

10. Official methods of analysis (AOAC), 12th Edition (1975), 16.035, 16.152, 16.166, and 16.178 .

11. Schlenker, R. A. and Kotek, T. J.: Effect of arm orientation on bone minera mass and bone width measured using the Cameron-Sorenson technique. Med. Phys., 6: 105 (1979).

12. Sorenson, J. A. and Cameron, J. R.: A reliable in vivo measurement of bone mineral content. J. Bone and Joint Surgery, 49-A: 481 (1967).

Copyright (C) 1983 International Pediatric Research Foundation, Inc $0031-3998 / 83 / 1704-0259 \$ 02.00 / 0$
13. Snyder, W. S., Cook, M. J., Nasset, E. S., Karhausen, L. R., Howells, G. P., and Tipton, I. H.: International Commission on Radiologic Protection. No. 23 Report of the Task Group on Reference Man, p. 63 (Pergamon Press, Oxford, 1974).

14. Steichen, J. J., Gratton, T. L., and Tsang, R. C.: Osteopenia of prematurity: the cause and possible treatment. J. Pediatr., 96: 528 (1980).

15. Witt, R. M.: Bone standards for the intercomparison and calibration of photon absorptiometric bone mineral measuring systems, in Mazess, R. B. (Ed.): International Conference on Bone Mineral Measurement, publication 75:683, U.S. Dept. of Health, Education and Welfare, 1974, pp. 114-122.

16. Presented in part before the Midwest Society for Pediatric Research, November 3-4, Detroit Michigan

17. Acknowledgements: Dr. Russell W. Chesney for advice used in preparation of the manuscript, Dr. Jean J. Steichen for supplying bones from premature infants for ashing studies, and Joan Chester, David Gardner, Tim Holmes, and John Stolp for technical assistance.

18. Requests for reprints should be addressed to: Dr. Frank R. Greer, Department of Pediatrics, Clinical Sciences Center, 600 Highland Avenue, Madison, WI 53792

19. Supported by a General Research Support Grant to the University of Wisconsin Medical School from the NIH, Division of Research Facilities and Resources, Bethesda, MD, and by a grant from the Graduate School, University of Wisconsin.

20. Received for publication March 9, 1982

21. Accepted for publication June 21, 1982. 